\title{
Helpers and egg investment in the cooperatively breeding acorn woodpecker: testing the concealed helper effects hypothesis
}

\author{
Walter D. Koenig • Eric L. Walters • Joseph Haydock
}

Received: 17 February 2009/Revised: 1 April 2009 / Accepted: 3 May 2009 /Published online: 20 May 2009

(C) The Author(s) 2009. This article is published with open access at Springerlink.com

\begin{abstract}
In cooperatively breeding acorn woodpeckers (Melanerpes formicivorus), helper males have a large positive effect on fledging success in good acorn crop years but only a small positive effect in poor acorn crop years, while helper females exhibit the opposite pattern. Based on these findings, we tested the "concealed helper effects" hypothesis, which proposes that laying females reduce investment in eggs (with respect to their size, number, or quality) in a way that confounds helper effects and results in an absence of a relationship between helpers and breeding success. Results generally failed to support the hypothesis. Mean egg size was positively related to temperatures during the 10 days prior to egg-laying and negatively related to the food supply as indexed by the prior fall's acorn crop, but there were no significant differences vis-à-vis helpers except for interactions with the acorn crop that only partly corresponded to those predicted. With respect to clutch size, females laid larger clutches when assisted by female helpers, opposite the pattern predicted.
\end{abstract}

Communicated by A. Cockburn

W. D. Koenig $(\triangle)$

Lab of Ornithology and Department of Neurobiology

and Behavior, Cornell University,

159 Sapsucker Woods Road,

Ithaca, NY 14850, USA

e-mail:wdk4@cornell.edu

E. L. Walters

Hastings Reservation and Museum of Vertebrate Zoology,

University of California Berkeley,

Carmel Valley, CA 93924, USA

J. Haydock

Department of Biology, Gonzaga University,

Spokane, WA 99258, USA
Although our results suggest that egg size is adjusted to particular ecological circumstances, we conclude that neither egg nor clutch size is adjusted in a way that confounds the apparent effects of helpers, as proposed by the concealed helper effects hypothesis.

Keywords Clutch size - Concealed helper effects . Cooperative breeding $\cdot$ Egg investment . Egg size

\section{Introduction}

Egg size, both absolute and relative to others within the same clutch, may significantly influence the competitiveness of hatchlings within the nest and the survivorship of offspring (Rutkowska and Cichon 2005; Taborsky et al. 2007). Consequently, varying egg size is one way that parental birds are able to affect the size and fitness of their young (Slagsvold et al. 1984; Grant 1991; Slagsvold and Amundsen 1992). Egg size has also been found to vary with either environmental conditions or parental quality in many studies (Wiebe and Bortolotti 1995; Horak et al. 1995; Potti 1999; Karell et al. 2008), adding an additional layer of complexity to the vast literature on avian investment strategies through varying clutch size.

Here, we investigate egg and clutch size variation in the cooperatively breeding acorn woodpecker (Melanerpes formicivorus) with the specific goal of testing for a relationship between these variables and access to supplemental provisioning provided by helpers that may enhance reproductive success. The hypothesis that females might adjust egg size depending on such aid has recently been proposed by Russell et al. (2007), who found that female superb fairy-wrens (Malurus cyaneus) breeding with helpers lay smaller eggs of lower nutritional quality than 
females breeding without helpers. This reduced maternal investment by females, subsequently compensated for by additional provisioning by helpers, offers a resolution to the paradox in fairy-wrens and potentially other cooperatively breeding species where the presence of helpers provides no clear enhancement of reproductive success (Dunn et al. 1995; Cockburn 1998; Magrath and Yezerinac 1997).

Like superb fairy-wrens, female acorn woodpeckers reduce their feeding rate when assisted by helpers, but the overall total feeding rate per chick increases with increasing group size (unpublished data). Thus, maternal loadlightening (Heinsohn 2004) occurs in both populations. In contrast to superb fairy-wrens, however, helpers and other additional group members in acorn woodpeckers are generally associated with increased number of young fledged per group (Koenig and Mumme 1987). More recent analyses (see below), however, indicate that there are significant differences in helper effects depending on the sex of helpers and on the size of the prior year's acorn crop, a critical food source for this species (Koenig and Mumme 1987). These differences in apparent helper effects suggest several specific predictions (detailed below) as to how breeding females should reduce investment in their eggs if they are engaged in a reproductive strategy similar to what has been described in fairy-wrens.

\section{Materials and methods}

Data and the study species

Acorn woodpeckers, a species common in central coastal California, breed in groups of up to 15 individuals of all ages and both sexes (Koenig et al. 1995a). Groups consist of a breeding core of individuals ranging from pairs to cooperatively polygynandrous groups of up to five cobreeder males competing for mating with one to three joint-nesting females plus a variable number of nonbreeding helpers that are offspring from prior years. Cobreeder males and joint-nesting females are almost always close relatives within a sex, often siblings or parents and their offspring, but breeder males are generally unrelated to breeder females (Koenig et al. 1998).

We studied a color-banded population of acorn woodpeckers at Hastings Reservation, central coastal California, between 1976 and 2008, during which time we monitored the population continuously and attempted to find all nesting attempts taking place within the study area. When nests were found prior to or during incubation, length and maximum width of eggs were measured to the nearest $0.1 \mathrm{~mm}$ using calipers. From these values, egg size was estimated from its volume as length $\times$ maximum width $^{2} \times$ pi/6 (Hoyt 1979).
In the earlier years of the study, we usually measured all eggs in a clutch. However, nests were often found only after or near clutch completion, so, we rarely knew egg order or, in the case of joint nests, the identity of laying females. Consequently, in later years, we sometimes measured only one or two randomly chosen eggs from a clutch. There was, however, no significant relationship between number of eggs measured in a clutch and any of the measures of egg size (length, maximum width, and estimated volume; $\left|r_{\mathrm{s}}\right| \leq 0.06$, $N=668$ clutches, all $P>0.14$ ). Thus, we used data from all clutches, whether we measured all eggs in the clutch or not, in our analyses. In general, clutch size and mean egg size across all eggs within the clutch (excluding runt eggs, discussed below) were used in analyses. The dates the first egg was laid (hereafter "first egg date") and last egg was laid ("last egg date") were usually back-calculated from the estimated or known hatch date. Given the short incubation period of 11 days and extensive information on nestling development in this population (Weathers et al. 1990), we are confident that our estimates of first and last egg date are accurate to within 2 days.

In all, we measured 2,526 eggs in 668 nests. Of these, 485 clutches were laid by 185 different color-banded females known to be the sole female breeder in the group. Since egg-dumping is rare in this population (Dickinson et al. 1995; Haydock et al. 2001), we are confident of maternity of these eggs. The majority of the remaining nests were joint nests of two females (Mumme et al. 1983; Koenig et al. 1995b) and were excluded from analysis because maternity of eggs was ambiguous. We did not attempt to analyze order effects, as we rarely knew the order in which eggs were laid.

Many nests of acorn woodpeckers (primarily, but not exclusively joint nests) are unique in that they contain strikingly small, inviable "runt" eggs (Koenig 1980a) whose function is unknown although they may be a manifestation of reproductive competition between jointnesting females (Koenig et al. 1995b). In any case, runt eggs appear to be laid in addition to a clutch of normal eggs (Koenig et al. 1995b) and are so small as to confound measurements of mean egg size; consequently, we excluded them from our analyses of egg and clutch size. For the purposes of this paper, runt eggs were defined as eggs whose volume was $<3.20$ cc (approximately the 99.9\% lower size cutoff for non-runt eggs laid in this population) and $<75 \%$ of the mean volume of all other eggs measured from the same clutch (Koenig 1980b). Thirty-eight $(2.3 \%)$ of 1,661 eggs measured laid by females nesting singly during the study met these criteria.

Although numerous environmental factors may influence reproduction in acorn woodpeckers, by far the most important is the size of the prior autumn's acorn crop (Koenig and Mumme 1987). Starting in 1980, the size of 
the acorn crop was assessed each year by visually counting acorns on 250 marked trees distributed among all five oak species present in the study area. The mean acorn crop was estimated by the mean of the log-transformed number of acorns counted in $30 \mathrm{~s}(\ln [N$ acorns counted +1$])$ across all trees surveyed (Koenig et al. 1994a, b). For some of the analyses performed here, years were divided into "good" acorn crop years (mean $\ln$-transformed number of acorns counted per $30 \mathrm{~s}>2, N=10$ ) and "poor" acorn crop years (mean $\ln$-transformed number of acorns counted per $30 \mathrm{~s}<$ $2, N=18$ ). As an additional variable potentially influencing egg size, we included the mean minimum temperature over the 10 days prior to the last egg date of each clutch as measured at the study site; 10 days was chosen to encompass conditions during and for several days prior to the laying of an average four to five egg clutch. Fall nests, which are attempted occasionally in good acorn crop years (Koenig and Stahl 2007), were not included in the analysis.

\section{Helper effects and the acorn crop}

Of 485 clutches laid by females nesting singly, 268 (55\%) were attended by groups containing one to six helper males (mean $\pm \mathrm{SD}=2.1 \pm 1.2$ ), of these, $108(22.3 \%)$ involved only male (i.e., no female) helpers. Similarly, 214 (44\%) clutches were attended by groups containing one to six helper females (mean $\pm \mathrm{SD}=1.6 \pm 0.8$ ), of which $54(11.1 \%$ ) involved only female helpers. Of the total number of clutches, 160 were attended by groups containing helpers of both sexes, and 163 (34\%) were attended by groups with no helpers at all. There was a significant correlation between the number of helper males in a group and the number of helper females $(r=0.29, N=386, P<0.001)$.

Overall, there was a strong relationship between annual reproductive success and number of helper males, total number of helpers, and group size, while there was no significant relationship between helper females and reproductive success (Table 1). These patterns, however, differed considerably depending on the prior year's acorn crop. In good acorn years, helper males had a strong positive effect on reproduction that carried over into a strong positive correlation between both the total number of helpers and group size with reproductive success, while the effect of helper females was slightly, but nonsignificantly, negative. In contrast, in poor acorn crop years, the effect of helper males was nonsignificant and less than a quarter of what it was during good years, while the effect of helper females was modestly positive but still nonsignificant. There were significant positive relationships between the total number of helpers and reproductive success and between group size and reproductive success in both good and poor acorn years, but the effect sizes in poor years were much smaller than in good acorn years (Table 1).

\section{Predictions and statistical tests}

If the patterns outlined in Table 1 involve concealed helper effects, two predictions follow. First, if the difference between male and female helpers is due to concealed helper effects, then females should lay smaller or fewer eggs when assisted by female helpers but not when assisted by male helpers. Second, if the differences between the apparent effects of male and female helpers in good vs poor acorn crop years is due to concealed helper effects, then females should lay smaller or fewer eggs when aided by male helpers in poor, but not good, acorn years, while there should be either no difference in egg or clutch size among females aided by female helpers between good and poor acorn years or the pattern should be opposite that predicted for helper males. Statistically, this pattern should reveal itself as a significant interaction between the acorn crop and the presence of male helpers, with egg or clutch size being smaller when the crop is poor. If there is an interaction

Table 1 Effects of helpers on annual reproductive success

\begin{tabular}{lllll}
\hline Model & Variables & Good acorn crop years & Poor acorn crop years & All years \\
\hline 1 & $N$ helper males & $\mathbf{0 . 4 5} \pm \mathbf{0 . 1 2}(<\mathbf{0 . 0 0 1})$ & $0.10 \pm 0.08(0.2)$ & $\mathbf{0 . 2 0} \pm \mathbf{0 . 0 7}(\mathbf{0 . 0 0 3})$ \\
1 & $N$ helper females & $-0.05 \pm 0.14(0.7)$ & $0.16 \pm 0.10(0.1)$ & $0.09 \pm 0.08(0.3)$ \\
2 & $N$ helpers & $\mathbf{0 . 2 4} \pm \mathbf{0 . 0 8}(\mathbf{0 . 0 0 2})$ & $\mathbf{0 . 1 2} \pm \mathbf{0 . 0 5}(\mathbf{0 . 0 2})$ & $\mathbf{0 . 1 5} \pm \mathbf{0 . 0 4}(<\mathbf{0 . 0 0 1 )}$ \\
3 & Group size & $\mathbf{0 . 2 3} \pm \mathbf{0 . 0 7}(\mathbf{0 . 0 0 1})$ & $\mathbf{0 . 1 5} \pm \mathbf{0 . 0 5}(\mathbf{0 . 0 0 2})$ & $\mathbf{0 . 1 6} \pm \mathbf{0 . 0 4}(<\mathbf{0 . 0 0 1 )}$ \\
& $N$ group years & 233 & 360 & 593 \\
\hline
\end{tabular}

Listed are effect sizes (regression coefficient \pm SE) with $P$ values in parentheses of group composition on number of young fledged determined by linear mixed-effects models controlling for $N$ breeder males, the prior year's acorn crop, and group history (whether there had been a turnover in breeders since the prior year or not) as fixed factors and group identity as a random factor. Included only are groups with a single breeder female; good and poor acorn crop years determined by visual surveys (see text). Model 1 includes $n$ helper males and $n$ helper females as separate fixed factors; model 2 includes total $N$ helpers as a fixed factor; model 3 combines helpers and breeders into a single variable of group size. Statistically significant values are in bold 
Table 2 Rationale and predictions of the concealed helper effects hypothesis

\begin{tabular}{llll}
\hline Test & Effect considered & Observation vis-à-vis reproductive success & Prediction vis-à-vis egg and clutch size \\
\hline 1 & Helper sex & Enhanced by helper males but not helper females & $\begin{array}{c}\text { Smaller when aided by helper females but not } \\
\text { when aided by helper males }\end{array}$ \\
2 & $\begin{array}{c}\text { Acorn crop } \times \text { helper } \\
\text { sex interaction }\end{array}$ & $\begin{array}{c}\text { Enhanced by helper males in good but not poor } \\
\text { acorn crop years; pattern with helper females } \\
\text { the opposite but not statistically significant }\end{array}$ & $\begin{array}{c}\text { Smaller when aided by helper males in good but not } \\
\text { poor acorn crop years; either no pattern or the } \\
\text { opposite pattern when aided by helper females }\end{array}$ \\
\hline
\end{tabular}

between the acorn crop and the presence of female helpers, it should be in the opposite direction, with egg or clutch size being smaller when the acorn crop is good. These predictions are summarized in Table 2.

To test these predictions, we performed linear mixed-effects models using groups containing a single breeder female. Included as fixed factors were $N$ breeder males, the mean logtransformed acorn crop from the prior autumn, the mean minimum temperature from the 10 days prior to the last egg date, the presence/absence of both helper males and helper females, and (for analyses of egg size) clutch size. Female identity was included as a random factor to control for maternal effects. Initial analyses included interaction terms between helper males and the acorn crop and between helper females and the acorn crop; however, the interaction terms were dropped when neither was statistically significant $(\alpha<$ 0.05). Statistical analyses were performed using R 2.6.2 ( $R$ Development Core Team 2008).

\section{Results}

Overall, egg size varied significantly depending on several variables (Table 3). Eggs were significantly wider and significantly larger in volume when temperatures prior to egg-laying were warmer and longer but significantly smaller in volume when the prior year's acorn crop was good. Clutch size did not vary significantly with either the prior year's acorn crop or mean minimum temperature prior to egg-laying. None of the variables considered varied significantly with the number of breeder males in the group. There was no significant relationship between clutch size and any of the three mean egg size variables.

Prediction 1: Females should lay smaller or fewer eggs when assisted by helper females but not helper males.

Contrary to prediction 1 , females laid significantly more, rather than fewer, eggs when assisted by female helpers (Table 3). Also, mean egg length was shorter when aided by male, but not female, helpers, again inconsistent with the hypothesis. There were no significant differences in egg size related to whether or not birds were aided by female helpers.

Prediction 2: In poor, but not good, acorn crop years, females should lay smaller or fewer eggs when aided by helper males; whereas, egg size or number should either not differ between good and poor acorn crop years or should be smaller in good acorn years when aided by helper females.

Prediction 2 posits a significant acorn crop $\times$ helper male interaction in the direction of egg or clutch size being

Table 3 Results of linear mixed-effects models testing for concealed helper effects on egg and clutch size in acorn woodpeckers

\begin{tabular}{lllll}
\hline Variables & Egg length & Egg width & Egg volume & Clutch size \\
\hline Male helpers & $-\mathbf{0 . 3 1} \pm \mathbf{0 . 1 1}(\mathbf{0 . 0 0 5})$ & $-0.02 \pm 0.07(0.8)$ & $-189 \pm 120(0.12)$ & $0.08 \pm 0.12(0.5)$ \\
Female helpers & $0.15 \pm 0.11(0.16)$ & $0.03 \pm 0.06(0.7)$ & $-167 \pm 114(0.14)$ & $\mathbf{0 . 3 6} \pm \mathbf{0 . 1 2}(\mathbf{0 . 0 0 3})$ \\
$N$ breeder males & $0.02 \pm 0.08(0.8)$ & $0.02 \pm 0.05(0.8)$ & $9 \pm 33(0.8)$ & $0.09 \pm 0.09(0.3)$ \\
Clutch size & $-0.04 \pm 0.04(0.4)$ & $-0.01 \pm 0.03(0.7)$ & $-13 \pm 18(0.5)$ & - \\
Acorn crop & $0.15 \pm 0.06(0.02)$ & $-0.07 \pm 0.04(0.07)$ & $-\mathbf{9 7} \pm \mathbf{4 4}(\mathbf{0 . 0 3})$ & $0.12 \pm 0.08(0.1)$ \\
Mean minimum temperature 10 days prior & $-0.00 \pm 0.02(0.8)$ & $\mathbf{0 . 0 3} \pm \mathbf{0 . 0 1}(\mathbf{0 . 0 1})$ & $\mathbf{1 6} \pm \mathbf{8}(\mathbf{0 . 0 4 7})$ & $-0.04 \pm 0.02(0.1)$ \\
$\quad$ to last egg date & $(\mathrm{NS})$ & $(\mathrm{NS})$ & $\mathbf{6 2} \pm 54(0.26)$ & $(\mathrm{NS})$ \\
Acorn crop $\times$ helper male interaction & $(\mathrm{NS})$ & $(\mathrm{NS})$ & $\mathbf{1 1 2} \pm \mathbf{5 5}(\mathbf{0 . 0 4})$ & $(\mathrm{NS})$ \\
Acorn crop $\times$ helper female interaction & & & \\
\hline
\end{tabular}

Analyses were restricted to nests with a single breeder female and included female identity as a random factor. Male and female helpers are coded as either being present or not present. Interactions between the acorn crop and helpers were omitted from analyses when both were nonsignificant (NS). $N=386$ clutches laid by 153 females. Statistically significant values are in bold; values are effect sizes \pm SE $(P$ value $)$ as in Table 1 
smaller in poor acorn years when assisted by male helpers. No such interaction was evident from the mixed-effects models, where none of the acorn crop $\times$ helper male interactions was significant (Table 3). There was, however, a significant acorn crop $\times$ helper female interaction in the analysis of egg volume. In order to visualize these results, we divided years into "good" and "poor" years as in Table 1, and plotted the mean effect of helper males and helper females on egg volume. The results (Fig. 1) suggest that, although not statistically significant, eggs were smaller in poor, but not good, acorn crop years when birds were assisted by helper males, as predicted. Helper females, however, exhibited the identical pattern, where the result was statistically significant.

\section{Discussion}

A major issue in the field of cooperative breeding has been to understand the fitness consequences of helpers. This has been particularly problematical in species in which helpers do not appear to increase reproduction (Cockburn 1998). In the case of acorn woodpeckers in central coastal California,

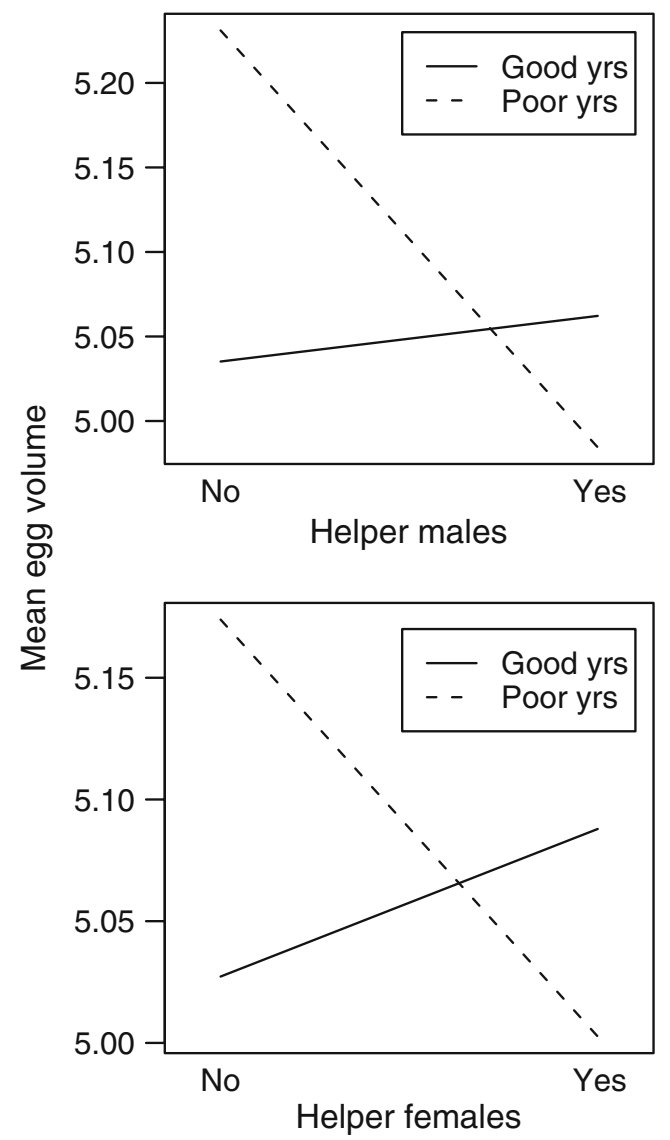

Fig. 1 Relationship between mean egg volume and the interaction between the acorn crop (divided into "good" and "poor" years) and the presence of helper males (top) and helper females (bottom) based on the linear mixed-effects model (Table 3 ) helpers overall correlate with increased reproductive success. However, the apparent fitness consequences of helpers differ depending on the year and the sex of the helpers. Male helpers enhance reproductive success, but considerably more so in good acorn crop years, when each helper corresponds to an additional 0.45 fledgling, than in poor acorn crop years, when each helper corresponds to only 0.10 offspring (Table 1$)$. In contrast, helper females do not significantly enhance reproductive success in either good or poor acorn crop years. This sex bias in helper effects is opposite the pattern of helper females increasing productivity more than helper males proposed by Cockburn (1998) to be a potentially general phenomenon in cooperative breeders. To the extent that females exhibit any pattern, it is the opposite of helper males, with helper females enhancing reproduction more in poor acorn crop years ( 0.16 offspring per helper) than in good acorn crop years, when their effect is on average slightly negative ( -0.05 offspring per helper). Despite these differences, the sex ratio of offspring is only slightly biased towards males (Koenig et al. 2001), and helper females are nearly as common as helper males in this population. Given their apparent failure to confer any fitness benefit, how can this high frequency of female helpers be explained?

One potential resolution of this paradox is that females invest less in eggs when assisted by helper females (in all years) and helper males (in poor acorn crop years), thus concealing the beneficial effects of helpers whose help subsequently serves to make up for the initial handicap conferred on the clutch by breeder females. This phenomenon of concealed helper effects has recently been documented in superb fairy-wrens (Russell et al. 2007), where females were found to lay smaller, lower-quality eggs when assisted by helpers, thus leading to helper effects that are otherwise not evident in the population. A similar case of apparently adaptive adjustment of offspring size has been documented in fishes by Taborsky et al. (2007), who found that female Neolamprologus pulcher (Cichlidae) lay smaller eggs when assisted by helpers, an effect they postulate is due to the lower predation suffered by offspring attended by helpers in this species. Whether a similar phenomenon occurs in other cooperatively breeding species has yet to be determined.

In the acorn woodpecker, the differences in apparent helper effects vis-à-vis the sex of helpers and the acorn crop suggest two predictions if concealed helper effects are present. First, females should lay smaller or fewer eggs when assisted by helper females but not helper males; and second, in poor, but not good, acorn crop years, females should lay smaller or fewer eggs when aided by helper males; whereas, either no pattern or the opposite pattern should hold for groups with helper females.

Contrary to the first prediction, birds did not lay smaller or fewer eggs when assisted by female helpers; rather, females laid significantly larger clutches when assisted by 
female helpers and significantly shorter eggs when assisted by helper males (Table 3). Consistent with the second prediction, females tended to lay smaller eggs in poor, but not good, acorn crop years when assisted by helper males. However, contrary to the prediction, the identical pattern was observed when females were assisted by helper females. Thus, when aided by helpers, females laid smaller eggs in poor acorn years and larger eggs in good acorn years (Fig. 1).

These results fail to support the concealed helper effects hypothesis in this population. The patterns revealed by these analyses do, however, suggest adaptive adjustment of egg size by females related to ecological conditions other than helpers, including environmental temperatures and the food supply as indicated by the prior year's acorn crop. The effects of these factors were not all clear-cut; for example, although eggs were significantly longer when the prior year's acorn crop was good, overall egg volume was significantly smaller in good acorn crop years, and there was no significant relationship between clutch size and the acorn crop. Thus, females in this population do not necessarily lay larger eggs when breeding conditions are favorable, as has been documented for other species (Cunningham and Russell 2000; Kontiainen et al. 2007). Even clutch size was not significantly related to resources in these analyses, although on an overall annual basis, there is a significant correlation between mean clutch size and the prior year's acorn crop ( $r=0.46, N=28$ years, $P=0.02)$.

One potential reason why the concealed helper effects hypothesis might fail is if females are unable to predict the amount or quality of help they can expect to receive (Russell et al. 2007), but this is not the case in acorn woodpeckers where helpers are generally offspring from prior years and are rarely failed breeders joining the group late in the season after eggs have hatched. Thus, breeding females should be able to assess the number of helpers likely to be present prior to the breeding season. A second reason would be if egg nutritional quality was adjusted by females independently of egg or clutch size (Nager et al. 2000) in a way that corresponds with the concealed helper effects model, a finding reported (along with reduced egg size) in superb fairy-wrens (Russell et al. 2007). We were not able to test for egg quality in this study, and thus the hypothesis that concealed helper effects are found in acorn woodpeckers cannot be completely rejected. However, insofar as the size or number of eggs laid by females is concerned, reduced maternal investment at the egg stage does not appear to be the general phenomenon in cooperative breeders proposed by Russell et al. (2007).

Within a clutch, varying egg size has the potential for allowing very fine adjustments of subsequent competitiveness within broods (Rutkowska and Cichon 2005). How- ever, at the level hypothesized by the concealed helper effects hypothesis, varying egg size is a relatively crude way of adjusting parental investment in reproduction compared to adjusting clutch size or feeding rates (Hatchwell 1999). Feeding, in particular, is an activity that takes place over a much longer time period and involves far more energy than the production of eggs. Consequently, we consider it unlikely that modifying egg size as a means of adjusting overall parental effort will turn out to be a common strategy in cooperative breeders. In contrast, load-lightening by breeders, reducing their feeding rates when assisted by helpers, is a commonly observed phenomenon in cooperative breeders (Hatchwell 1999; Heinsohn 2004). Loadlightening offers a potential alternative explanation for the failure of some cooperative species to exhibit an increase in reproductive success with group size if breeders reduce their own investment when assisted by helpers such that the total feeding rate remains constant (Hatchwell 1999).

In the case of acorn woodpeckers, analyses suggest not only that females reduce their feeding rate when assisted by helpers, but that, like superb fairy-wrens, breeder females reduce their feeding rate more in response to the presence of helpers than to changes in brood size (unpublished data), a result indicating that the marginal costs of parental care are greater than the marginal benefits (Hatchwell 1999; Russell et al. 2008). Thus, adjustments of parental care are being made in the acorn woodpecker relative to helper presence, but for the most part, these adjustments appear to be primarily at the nestling rather than the egg stage.

Acknowledgements We thank the National Science Foundation for support, most recently through grant IOB-0516851, and the reviewers for their thoughtful comments. We also thank Mark Stanback, Ron Mumme, and Bill Carmen for their contributions to the data used in the analyses and our field assistants for their help monitoring the population.

Open Access This article is distributed under the terms of the Creative Commons Attribution Noncommercial License which permits any noncommercial use, distribution, and reproduction in any medium, provided the original author(s) and source are credited.

\section{References}

Cockburn A (1998) Evolution of helping behavior in cooperatively breeding birds. Annu Rev Ecol Syst 29:141-177

Cunningham EJA, Russell AF (2000) Egg investment is influenced by male attractiveness in the mallard. Nature 404:74-77

Dickinson JL, Haydock J, Koenig WD, Stanback MT, Pitelka FA (1995) Genetic monogamy in single-male groups of acorn woodpeckers. Mol Ecol 4:765-770

Dunn PO, Cockburn A, Mulder RA (1995) Fairy-wren helpers often care for young to which they are unrelated. Proc R Soc Lond B Biol Sci 259:339-343

Grant MC (1991) Relationships between egg size, chick size at hatching and chick survival in the whimbrel Numenius phaeopus. Ibis 133:127-133 
Hatchwell BJ (1999) Investment strategies of breeders in avian cooperative breeding system. Am Nat 154:205-219

Haydock J, Koenig WD, Stanback MT (2001) Shared parentage and incest avoidance in the cooperatively breeding acorn woodpecker. Mol Ecol 10:1515-1525

Heinsohn RG (2004) Parental care, load-lightening and costs. In: Koenig WD, Dickinson JL (eds) Ecology and evolution of cooperative breeding in birds. Cambridge University Press, Cambridge, pp 67-80

Horak P, Mand R, Ots I, Leivits A (1995) Egg size in the great tit Parus major: individual, habitat and geographic differences. Ornis Fenn 72:97-114

Hoyt DF (1979) Practical methods of estimating volume and fresh weight of bird eggs. Auk 96:73-77

Karell P, Kontiainen P, Pietiäinen H, Siitari H, Brommer JE (2008) Maternal effects on offspring Igs and egg size in relation to natural and experimentally improved food supply. Funct Ecol 22:682-690

Koenig WD (1980a) The incidence of runt eggs in woodpeckers. Wilson Bull 92:169-176

Koenig WD (1980b) The determination of runt eggs in birds. Wilson Bull 92:103-107

Koenig WD, Mumme RL (1987) Population ecology of the cooperatively breeding acorn woodpecker. Princeton University Press, Princeton

Koenig WD, Stahl JT (2007) Late summer and fall nesting in the acorn woodpecker and other North American terrestrial birds. Condor 109:334-350

Koenig WD, Mumme RL, Carmen WJ, Stanback MT (1994a) Acorn production by oaks in central coastal California: variation within and among years. Ecology 75:99-109

Koenig WD, Knops JMH, Carmen WJ, Stanback MT, Mumme RL (1994b) Estimating acorn crops using visual surveys. Can J For Res 24:2105-2112

Koenig WD, Stacey PB, Stanback MT, Mumme RL (1995a) Acorn woodpecker (Melanerpes formicivorus). In: Poole A, Gill F (eds) The birds of North America, No. 194. Academy of Natural Sciences and American Ornithologists' Union, Washington DC

Koenig WD, Mumme RL, Stanback MT, Pitelka FA (1995b) Patterns and consequences of egg destruction among joint-nesting acorn woodpeckers. Anim Behav 50:607-621

Koenig WD, Haydock J, Stanback MT (1998) Reproductive roles in the cooperatively breeding acorn woodpecker: incest avoidance versus reproductive competition. Am Nat 151:243-255
Koenig WD, Stanback MT, Haydock J, Kraaijeveld-Smit F (2001) Nestling sex ratio variation in the cooperatively breeding acorn woodpecker (Melanerpes formicivorus). Behav Ecol Sociobiol 49:357-365

Kontiainen P, Brommer JE, Karell P, Pietiäinen H (2007) Heritability, plasticity and canalization of Ural owl egg size in a cyclic environment. J Evol Biol 21:88-96

Magrath RD, Yezerinac SM (1997) Facultative helping does not influence reproductive success or survival in cooperatively breeding white-browed scrubwrens. J Anim Ecol 66:658-670

Mumme RL, Koenig WD, Pitelka FA (1983) Reproductive competition in the communal acorn woodpecker: sisters destroy each other's eggs. Nature 306:583-584

Nager RG, Monaghan P, Houston DC (2000) Within-clutch trade-offs between the number and quality of eggs: experimental manipulations in gulls. Ecology 81:1339-1350

Potti J (1999) Maternal effects and the pervasive impact of nestling history on egg size in a passerine bird. Evolution 53:279-285

R Development Core Team (2008) R: a language and environment for statistical computing. R Foundation for Statistical Computing, Vienna, Austria. ISBN 3-900051-07-0, URL http://www.R-project.org

Russell AF, Langmore NE, Cockburn A, Astheimer LB, Kilner RM (2007) Reduced egg investment can conceal helper effects in cooperatively breeding birds. Science 317:941-944

Russell AF, Langmore NE, Gardner JL, Kilner RM (2008) Maternal investment tactics in superb fairy-wrens. Proc R Soc Lond B Biol Sci 275:29-36

Rutkowska J, Cichon M (2005) Egg size, offspring sex and hatching asynchrony in zebra finches Taeniopygia guttata. J Avian Biol 36:12-17

Slagsvold T, Amundsen T (1992) Do great tits adjust hatching spread, egg size and offspring sex ratio to changes in clutch size? J Anim Ecol 61:249-158

Slagsvold T, Sandvik J, Rofstad G, Lorentsen Ö, Husby M (1984) On the adaptive value of intraclutch egg-size variation in birds. Auk 101:685-697

Taborsky B, Skubic E, Bruintjes R (2007) Mothers adjust egg size to helper number in a cooperatively breeding cichlid. Behav Ecol Sociobiol 18:652-657

Weathers WW, Koenig WD, Stanback MT (1990) Breeding energetics and thermal ecology of the acorn woodpecker in central coastal California. Condor 92:341-359

Wiebe KL, Bortolotti GR (1995) Egg size and clutch size in the reproductive investment of American kestrels. J Zool 237:285-301 